\title{
FUNGOS FILAMENTOSOS ISOLADOS DE FOLHAS EM DECOMPOSIÇÃO NA REPRESA DE GUARAPIRANGA, SÃO PAULO, SP
}

\section{FILAMENTOUS FUNGI ISOLATED FROM LEAVES IN DECOMPOSITION IN THE GUARAPIRANGA RESERVOIR, SÃO PAULO, SP}

\section{Wellbaum, C. ${ }^{1 \ddagger}$, Schoenlein-Crusius, I. H. ${ }^{2}$, Malosso, E. ${ }^{3}$, Tauk-Tornisielo, S. M. ${ }^{1}$}

${ }^{1}$ Centro de Estudos Ambientais, CEA, Universidade Estadual Paulista, UNESP, Campus de Rio Claro, Avenida 24-A, 1515, Bela Vista, CEP 13.506-900, Rio Claro, SP. E-mail seb@rc.unesp.br

${ }^{2}$ Instituto de Botânica, Secretaria do Meio Ambiente, SMA, do Estado de São Paulo.Avenida Miguel Stéfano, 3687, Água Funda, CEP 04301-902, São Paulo, SP. E-mail iracema@crusius.com.br

${ }^{3}$ Universidade Federal de Pernambuco, UFPE, Departamento de Micologia Rua Prof. Nelson Chaves, $\mathrm{s} / \mathrm{n}^{\circ}$.

\section{RESUMO}

No presente estudo, são apresentados os resultados sobre o levantamento da diversidade da micota das folhas em decomposição, de sete coletas bimestrais (agosto de 1997 a agosto de 1998) em ambientes terrestre e aquático localizados nas seis estações de coleta às margens da Represa do Guarapiranga, no município de São Paulo, SP. O isolamento dos fungos foi realizado através da técnica de lavagem de discos de folhas que foram plaqueados em meio de cultura (batata-dextrose-ágar, BDA). Macro e micronutrientes foram determinados nas alíquotas remanescentes das folhas, e durante as coletas foram determinados $\mathrm{o} \mathrm{pH}$, condutividade, oxigênio dissolvido (OD) e a temperatura da água. Os fungos associados às folhas em decomposição do ambiente terrestre (46 táxons) e do aquático (54 táxons) apresentaram elevada similaridade (68\%) entre si. A tendência encontrada foi de que as micotas abrangeram grupos considerados cosmopolitas, com predomínio de representantes de Penicillium, Fusarium, Trichoderma e Pestalotiopsis. A possível influência dos fatores climáticos foi diferente sobre os dois ambientes. Observou-se a existência de três efeitos antrópicos diretos sobre os teores de nutrientes de folhas, bem como sobre a diversidade e quantidade de fungos: o despejo de poluentes 
orgânicos, a aplicação de sulfato de cobre nas águas e a modificação da vegetação da represa.

Palavras-chave: Fungos. Biodiversidade. Folhas em decomposição. Poluição antrópica. Represa.

\section{ABSTRACT}

In this study, the mycota diversity of decomposing leaves was surveyed from seven bimonthly collections (August/1997 to ugust/1998) in the terrestrial and aquatic environments in six collection stations along the borders of the Guarapiranga reservoir, in São Paulo, SP. The fungi isolation was carried out using the leaf disk washing technique, followed by plating on culture media (Potato dextrose agar). Macro and micronutrients were determined in the remaining aliquots of the leaves, and during the collections, parameters such as $\mathrm{pH}$, conductivity, dissolved oxygen (OD) and water temperature were also determined. The fungi associated with the decomposing leaves of the terrestrial (46 taxa) and aquatic (54 taxa) environments presented high similarity $(68 \%)$ between them. The mycota included cosmopolite fungi groups, with predominance of Penicillium, Fusarium, Trichoderma and Pestalotiopsis species. The possible influence of climatic factors was different in the two environments. Three antropic effects on the leaf nutrient content were observed, as well as on the fungi diversity and quantity: the dumping of organic pollutants, copper sulfate application in the water, and the vegetation modification of the reservoir.

Keywords: Fungi. Biodiversity. Decomposition leaves. Antropic pollution. Reservoir

\section{INTRODUÇÃO}

A análise da biodiversidade terá mais crédito quando maior número de grupos taxonômicos e funcionais de organismos heterotróficos for incluído nas investigações (SYMONIDES, 1992), uma vez que a escolha de locais para conservação da biodiversidade, baseada em classificação ou mapeamento vegetal, não leva em conta as comunidades microbianas. Desta forma importantes espécies podem ser perdidas (NANTEL; NEUMANN, 1992), com conseqüências desconhecidas para a manutenção da vida nos ambientes terrestre e aquático.

Um pré-requisito essencial para a análise da estrutura e do funcionamento de um ecossistema é a informação sobre biomassa, produtividade e diversidade dos organismos que regem os processos básicos nele existentes. A decomposição é parte importante no ciclo de nutrientes, pois os elementos essenciais da biomassa morta tornam-se novamente disponíveis para o crescimento de novas plantas (GESSNER; CHAUVET, 1994). 
O entendimento do distúrbio humano sobre a diversidade fúngica nos trópicos é de vital importância para a conservação eficiente dos recursos renováveis e dos ecossistemas (TSUI et al., 1998). Apesar dos fungos terem importante participação no funcionamento dos ecossistemas aquáticos, as informações sobre sua resposta à poluição são escassas (MALTBY; BOOTH, 1991).

A fundamental deficiência de conhecimento básico sobre os fungos nos trópicos significa que é muito difícil de se explorar essa questão, pois somente um número limitado de estudos está disponível para promover dados relevantes, havendo quase nenhuma informação especificamente de distúrbios antrópicos sobre a micota nos trópicos (TAUK-TORNISIELO; RUEGGER, 1987, TAUK-TORNISIELO, 1988, TAUK-TORNISIELO et al., 1990a, 1990b, TSUI et al., 1998). Contudo, existem várias revisões dos efeitos da influência humana sobre comunidades fúngicas, mas a maioria é restrita aos efeitos no solo ou sobre a comunidade micorrízica em regiões temperadas (ZAK, 1992, MILLER; LODGE, 1997).

Assim como o solo das florestas, os sistemas aquáticos recebem e retêm grandes quantidades de folhas, derivadas da vegetação marginal, que suprem suas necessidades de carbono e energia. A estrutura e funcionamento dos sistemas aquáticos são dependentes, portanto, da matéria orgânica alóctone. A quebra desse material constitui o processo chave no metabolismo dos sistemas aquáticos. Os fungos, portanto, são mediadores do fluxo de energia e de nutrientes para os outros níveis tróficos, pois decompõe a matéria orgânica nos seus componentes originais, devolvendo-os ao ciclo de nutrientes (BÄRLOCHER, 1985, GESSNER; CHAUVET, 1994).

Como organismos cosmopolitas e diversificados, os fungos exercem papel de relevância nos diferentes ecossistemas que integram (BERGAMIN; KIMATI, 1995). Conhecendo suas funções nos ecossistemas, é possível avaliar devidamente qualquer tipo de intervenção antrópica. Assim, alterações podem ser evitadas ou minimizadas e as medidas da preservação ou recuperação dos ecossistemas tornam-se facilitadas (MILANEZ, 1995). A sensibilidade dos fungos frente a vários poluentes e compostos químicos não é clara. A documentação da biodiversidade e mais pesquisas englobando os efeitos de distúrbios sobre o funcionamento do ecossistema são necessárias devido à deficiência deste tipo de estudo nos trópicos envolvendo fungos (TSUI et al., 1998).

O conceito de biodiversidade envolve tanto uma dimensão quantitativa, número e variedade de genes, espécies e ecossistemas, quanto qualitativa, isto é, o estado das realidades biológicas e dos ambientes onde ocorrem. A biodiversidade, na verdade, é um termo amplo utilizado para definir o grau de variedade encontrado na natureza (HAILA; KOUKI, 1994).

Nesse sentido o presente estudo procurou dar subsídios para avaliação e conservação da biodiversidade de fungos, documentando a diversidade da micota das folhas em decomposição coletadas do ambiente aquático e terrestre da Represa do Guarapiranga, município de São Paulo e verificando possíveis efeitos causados pela 
influência antrópica sobre a diversidade dos fungos decompositores sobre os nutrientes contidos nas folhas, bem como sobre os parâmetros abióticos mensurados.

\section{1. Área de Estudo}

A Represa do Guarapiranga, situada no extremo da zona sul da região metropolitana de São Paulo (a $23^{\circ} 43^{\prime}$ latitude Sul e $46^{\circ} 36^{\prime}$ longitude Oeste a uma altitude de $740 \mathrm{~m}$ ) é formada pelo represamento do Rio Guarapiranga e dos afluentes Lavra, Santa Rita, Embú-Guaçu, Embú-Mirim e de outros 17 córregos. A área de drenagem da bacia corresponde a $631 \mathrm{~km}^{2}$ e sua vazão de $9,5 \mathrm{~m}^{3} \cdot \mathrm{s}^{-1}$. A bacia apresenta quatro áreas com características distintas: Bororé, Riviera, Embú e Itapecerica da Serra, todas com urbanização intensa. Os núcleos de Parelheiros, Cipó e Embú-Guaçú apresentam áreas com ocupação esparsa, áreas ocupadas com chácaras de recreio, loteamentos com baixa densidade ou ainda não ocupados, existindo também áreas rurais mais periféricas. Aproximadamente 3 milhões de habitantes são beneficiados com o abastecimento da Represa do Guarapiranga, que é responsável por cerca de $20 \%$ do abastecimento da região metropolitana de São Paulo. Apesar de constituir área de preservação ambiental, a represa tem sofrido diversos tipos de influência antrópica como: loteamentos clandestinos, desmatamento das suas margens e principalmente lançamento de esgotos domésticos (COMPANHIA DE TECNOLOGIA DE SANEAMENTO AMBIENTAL, 1998) gerados por cinco municípios $\left(33,4\right.$ ton $\left.\mathrm{DBO}_{5} \mathrm{dia}^{-1}\right)$ além de receber efluentes industriais $\left(0,7\right.$ ton $\mathrm{DBO}_{5} \operatorname{dia}^{-1}$ a 1,8 ton $\left.\mathrm{DBO}_{5} \operatorname{dia}^{-1}\right)$.

Atualmente o manancial é administrado, fiscalizado e monitorado pelos órgãos CETESB - Companhia de Tecnologia de Saneamento Ambiental e SABESP Companhia de Saneamento Básico do Estado de São Paulo. Devido ao despejo de esgoto clandestino na represa, por via direta ou pelos córregos afluentes, a SABESP tem promovido regularmente o pré-tratamento das águas com algicidas, tais como o sulfato de cobre e peróxido de hidrogênio. Esse procedimento tem como finalidade principalmente o controle da proliferação de algas, o que facilitaria o tratamento da água para o consumo. No início da década de 80 foram lançadas doses de 10 a 12 toneladas por mês de sulfato de cobre em faixas delimitadas na represa. Posteriormente, essas doses foram reduzidas para 3 a 4 toneladas por mês (CETESB 1992, 1998). Além disso, alguns trechos das margens da represa, bem como das pequenas ilhas nela situadas, estão sofrendo rápido assoreamento, possivelmente em resposta às oscilações do volume de água contido no manancial, com conseqüente queda de árvores para o interior do corpo d'água, agravando ainda mais o processo de eutrofização da represa. 


\section{MATERIAL E MÉTODOS}

\subsection{Coleta e Tratamento das Amostras}

Foram escolhidos seis pontos de coleta ao longo das margens da Represa do Guarapiranga, definidos pelo grau de ação antrópica na região (Quadro 1). A escolha desses locais foi estabelecida de acordo com as estações de coleta usadas para monitoramento regular da água pela SABESP.

Quadro 1. Tipo de influência antrópica existente na Represa do Guarapiranga, no município de São Paulo, SP.

\begin{tabular}{c|ll}
\hline $\mathbf{N}^{\mathbf{0}}$ & \multicolumn{1}{|c}{ Nome } & Tipo de Influência Antrópica \\
\hline $\mathbf{1}$ & $\begin{array}{l}\text { Parque do } \\
\text { Guarapiranga }\end{array}$ & $\begin{array}{l}\text { Área de lazer, com predominância de eucaliptos, local da captação de água para o } \\
\text { abastecimento e alto impacto antrópico: lançamento periódico de doses altas de sulfato } \\
\text { de cobre. }\end{array}$ \\
$\mathbf{2}$ & $\begin{array}{l}\text { Clube Castelo } \\
\text { Área de recreação, com pouca vegetação (só grama e Eucalyptus spp.), águas bastante } \\
\text { poluídas pelos córregos saturados de esgoto que fluem na sua área, recebeu pouco } \\
\text { sulfato de cobre; esse local ainda sofre a retirada constante da serapilheira. }\end{array}$ \\
$\mathbf{4}$ & $\begin{array}{l}\text { Alube de Campo } \\
\text { São Paulo } \\
\text { Ilha dos Eucaliptos } \\
\text { pouco poluídas, não recebeu aplicação de sulfato de cobre durante o período estudado. } \\
\text { Localiza-se na porção central da represa, portanto suas águas recebem a poluição de } \\
\text { diversos pontos, parte da vegetação é preservada e a outra está em estágios iniciais de } \\
\text { recuperação, recebeu pouco sulfato de cobre. }\end{array}$ \\
$\mathbf{5}$ & $\begin{array}{l}\text { Desembocadura do } \\
\text { Rio Embú-Guaçu } \\
\text { Marina Riviera }\end{array}$ & $\begin{array}{l}\text { Área de difícil acesso com vegetação exuberante e bem preservada é a estação com as } \\
\text { águas limpas, não recebeu algicidas. } \\
\text { Área residencial, com pouca diversidade vegetal, águas bastante poluídas pelo Córrego } \\
\text { Itupu e pelo Ribeirão Guavirutuba, recebeu bastante sulfato de cobre. }\end{array}$ \\
\hline
\end{tabular}

No período de agosto de 1997 a agosto de 1998 foram realizadas sete coletas bimestrais, nas quais se coletaram amostras de aproximadamente $300 \mathrm{~g}$ de folhedo misto da superfície do solo e $300 \mathrm{~g}$ de folhedo submerso às margens da Represa, para isolamento dos fungos e para fins de análises químicas. Coletaram-se também amostras de $150 \mathrm{~mL}$ de água para análise da condutividade e material em suspensão e ainda, amostras de $350 \mathrm{~mL}$ de água em frascos de Winkler para determinação do oxigênio dissolvido (OD).

A temperatura do ar foi medida através de um termômetro de mercúrio e as medidas do índice de precipitação foram obtidas na Estação Meteorológica do Instituto Astronômico e Geofísico da Universidade de São Paulo. Durante as coletas foram determinados os seguintes parâmetros na água: $\mathrm{pH}$, $\mathrm{OD}$, temperatura e condutividade (Horiba U-10).

\subsection{Nutrientes dos Folhedos dos Ambientes Aquático e Terrestre}

As determinações de macro e micronutrientes das folhas coletadas foram realizadas pelo Departamento de Solos da Escola Superior de Agricultura "Luiz de Queiroz”, ESALQ, no município de Piracicaba, SP. 


\subsection{Isolamento e Quantificação dos Fungos das Folhas Coletadas}

$\mathrm{O}$ isolamento dos fungos foi conduzido pela técnica da lavagem de discos de folhas (PUGH et al., 1972) seguida do plaqueamento destes em meio de cultura. De cada amostra foram cortados 15 discos de folhas com $5 \mathrm{~mm}$ de diâmetro com vazador de rolhas, que foram lavados 20 vezes vigorosamente com água destilada e esterilizada. Os discos foram colocados eqüidistantes em grupos de cinco em placasde-petri com meio de cultura BDA (batata-dextrose-ágar), em triplicata. As placas foram incubadas a temperatura ambiente $\left(20-25^{\circ} \mathrm{C}\right)$, de cinco a sete dias. As colônias que se desenvolveram ao redor dos discos de folhas foram quantificadas e purificadas e em seguida transferidas para meios de cultura específicos (ágar-cravo, Czapeck, SMA) de acordo com os grupos taxonômicos, para proceder suas identificações.

Além do isolamento e purificação das colônias e da observação e medição de estruturas macro e microscópicas dos fungos, que são procedimentos usuais de identificação, utilizou-se à técnica do cultivo em lâmina (RIDDELL, 1950, MYCOLOGY GUIDEBOOK COMMITTEE, 1970) para melhor observação do crescimento e desenvolvimento das estruturas de reprodução e/ou dispersão. A esterilização de todo material utilizado e dos meios de cultura foi realizada de 120 a $127^{\circ} \mathrm{C}$, a $1,5 \mathrm{~atm}$, durante 30 minutos.

\subsection{Análise dos Resultados}

Foi realizada a análise estatística através do teste de análise de variância com dois fatores (datas de coleta/estações de coleta), com réplicas. O teste estatístico de Tukey foi aplicado, quando houve diferença estatisticamente significativa quanto aos fatores aplicados. Foi também realizado o teste de correlação de Spearman para evidenciar possíveis correlações entre as variáveis bióticas e abióticas aqui estudadas. Aplicou-se o teste de similaridade de Sorensen, apud Tauk-Tornisielo (2005) para o cálculo de similaridade entre as micotas isoladas, comparando-se as estações de coleta, os meses e os dois tipos de ambientes. O tratamento estatístico dos resultados aqui obtidos foi recomendado e conduzido em programa SAS versão 6.12.

\section{RESULTADOS E DISCUSSÃO}

\subsection{Diversidade e Quantificação dos Fungos}

Foram isoladas 66 táxons de fungos, número considerado alto quando comparado com a literatura, dos quais 41 táxons foram reportados pela primeira vez no local de estudo. Foram isolados 46 táxons do folhedo em decomposição do ambiente terrestre (Tabela 1a) e 54 táxons do folhedo submerso às margens da represa (Tabela 1b). 


\begin{tabular}{|l|r|}
\hline Recebido em: $02 / 03 / 2006$ & HOLOS Environment, v.7 n.2, 2007 - P. 177 \\
\hline Liberado para Publicação em: $10 / 11 / 2007$ & ISSN:1519-8634 (ON-LINE) \\
\hline
\end{tabular}

Tabela 1a - Ocorrências (X: presença) dos fungos isolados pela técnica da lavagem de discos de folhas seguida por plaqueamento em meio de cultura, associados ao folhedo coletado no ambiente terrestre (folhas secas) às margens da Represa do Guarapiranga, no município de São Paulo, de agosto de 1997 a agosto de 1998.

Fungos

Fungos anamórfos

1Alternaria alternata (?)

2 Aureobasidium pullulans

3 Beltrania rhombica

4 Beltraniella spp.

5 Camarosporium sp.

6Cladosporium cladosporioides

7 Cladosporium shaerospermum

8 Colletotrichum gloesporioides

9 Colletotrichum orbiculare

10Curvularia brachyspora

11Curvularia harveni

12 Curvularia lunata

13 Cylindrocladium scoparium

14Epicoccum nigrum

15 Fusarium sambucinum

16Fusarium solani

17 Gloesporium sp.

18 Inseticola clavata

19 Marssonina fragariae

20 Penicillium citrinum

21 Penicillium erythromitellis

22 Penicillium islandicum

23 Penicillium novae-zeelandiae

24Penicillium piceum

25Penicillium rugulosum

26Penicillium variabile

27Penicillium waksmanii

28Pestalotiopsis sp.1(?)

29Pestalotiopsis sp.2(?)

30Phoma glomerata

31 Phoma jolyana

32Selenophoma asterina

33Selenophoma spp.

34Shaeropsidales sp.1

35Shaeropsidales sp.3

36Trichoderma hamatum

37Trichoderma harzianum

38Trichoderma longibrachiatum

39Trichoderma pseudokoningi

40Trichoderma viride

41Fungo negro estéril

Mastigomycota

42Pythium spp. (estéril)

Zygomycota

43Mucor hiemalis

Ascomycota

44Ascomiceto 1

45Ascomiceto 2

Basidiomycota

46Cultura branca

\begin{tabular}{|c|c|c|c|c|c|c|c|}
\hline 46Cultura branca & & & & $\mathrm{X}$ & & & \\
\hline Totais & 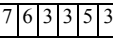 & \begin{tabular}{|l|l|l|l|l|l|}
5 & 2 & 5 & 4 & 0 & 3 \\
\end{tabular} & \begin{tabular}{|l|l|l|l|l|l|}
4 & 1 & 2 & 4 & 6 & 4 \\
\end{tabular} & \begin{tabular}{|l|l|l|l|l|l|}
4 & 5 & 5 & 4 & 6 & 4 \\
\end{tabular} & \begin{tabular}{l|l|l|l|l|l}
5 & 7 & 8 & 5 & 9 & 8 \\
\end{tabular} & \begin{tabular}{|l|l|l|l|l|l|}
4 & 11 & 5 & 5 & 3 & 11 \\
\end{tabular} & \begin{tabular}{|l|l|l|l|l|l|}
9 & 4 & 3 & 5 & 3 & 3 \\
\end{tabular} \\
\hline Totais de ocorrências por coleta & 27 & 19 & 21 & 28 & 42 & 39 & 27 \\
\hline Espécies por coleta & 13 & 10 & 13 & 15 & 24 & 18 & 16 \\
\hline
\end{tabular}

Coletas realizadas nas seis estações de coletas

\begin{tabular}{|c|c|c|c|c|c|c|}
\hline Ago./97 & Out./97 & Dez./97 & Fev./98 & Abr./98 & Jun./98 & Ago./98 \\
\hline \multicolumn{7}{|c|}{ Estações de coletas } \\
\hline
\end{tabular}

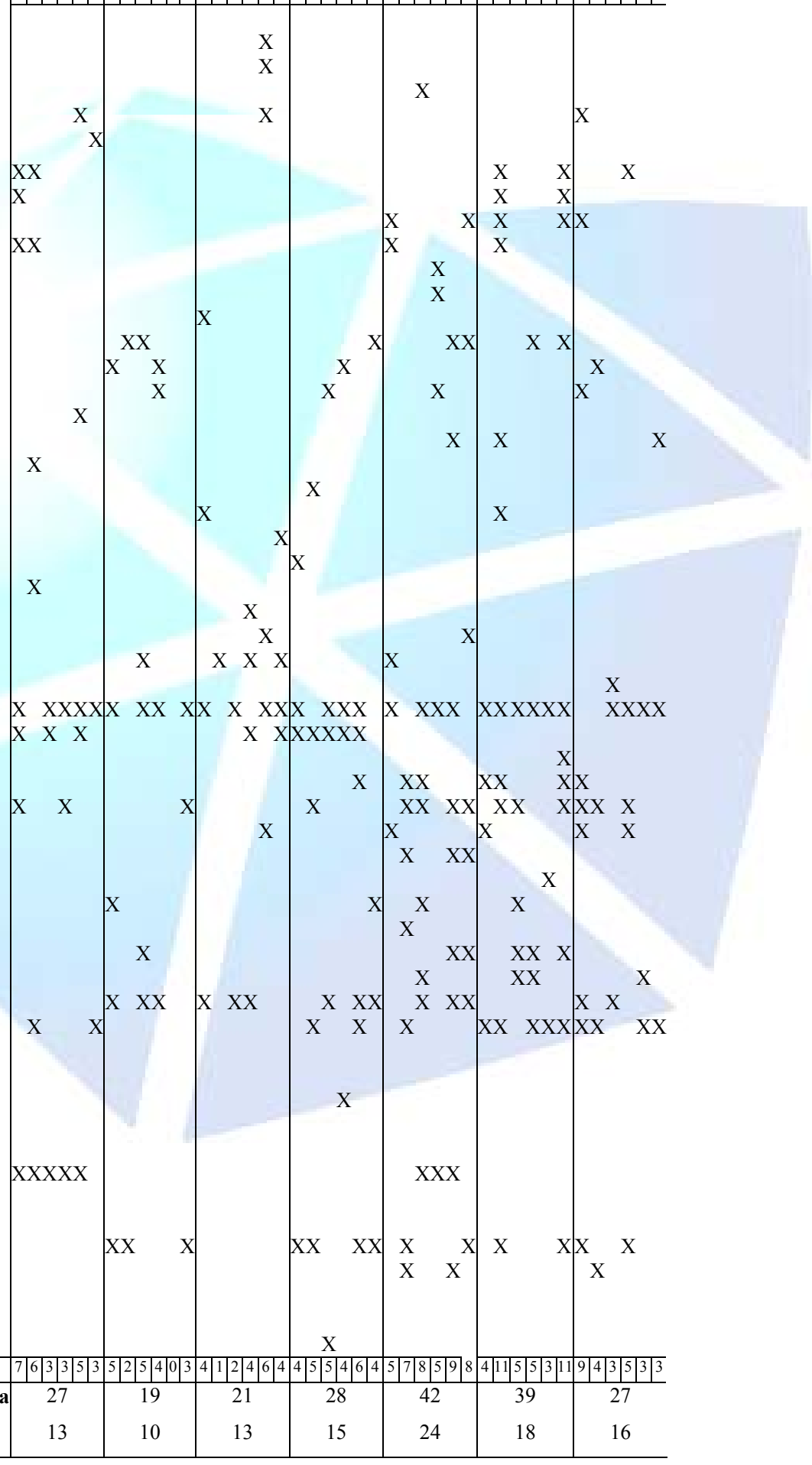




\begin{tabular}{|l|r|}
\hline Recebido em: $02 / 03 / 2006$ & HOLOS Environment, v.7 n.2, 2007 - P. 178 \\
\hline Liberado para Publicação em: $10 / 11 / 2007$ & ISSN:1519-8634 (ON-LINE) \\
\hline
\end{tabular}

Tabela $1 \mathrm{~b}$ - Ocorrências (X: presença) dos fungos isolados pela técnica da lavagem de discos de folhas seguida por plaqueamento em meio de cultura, associados ao folhedo coletado no ambiente aquático, às margens da Represa do Guarapiranga, no município de São Paulo, de agosto de 1997 a agosto de 1998.

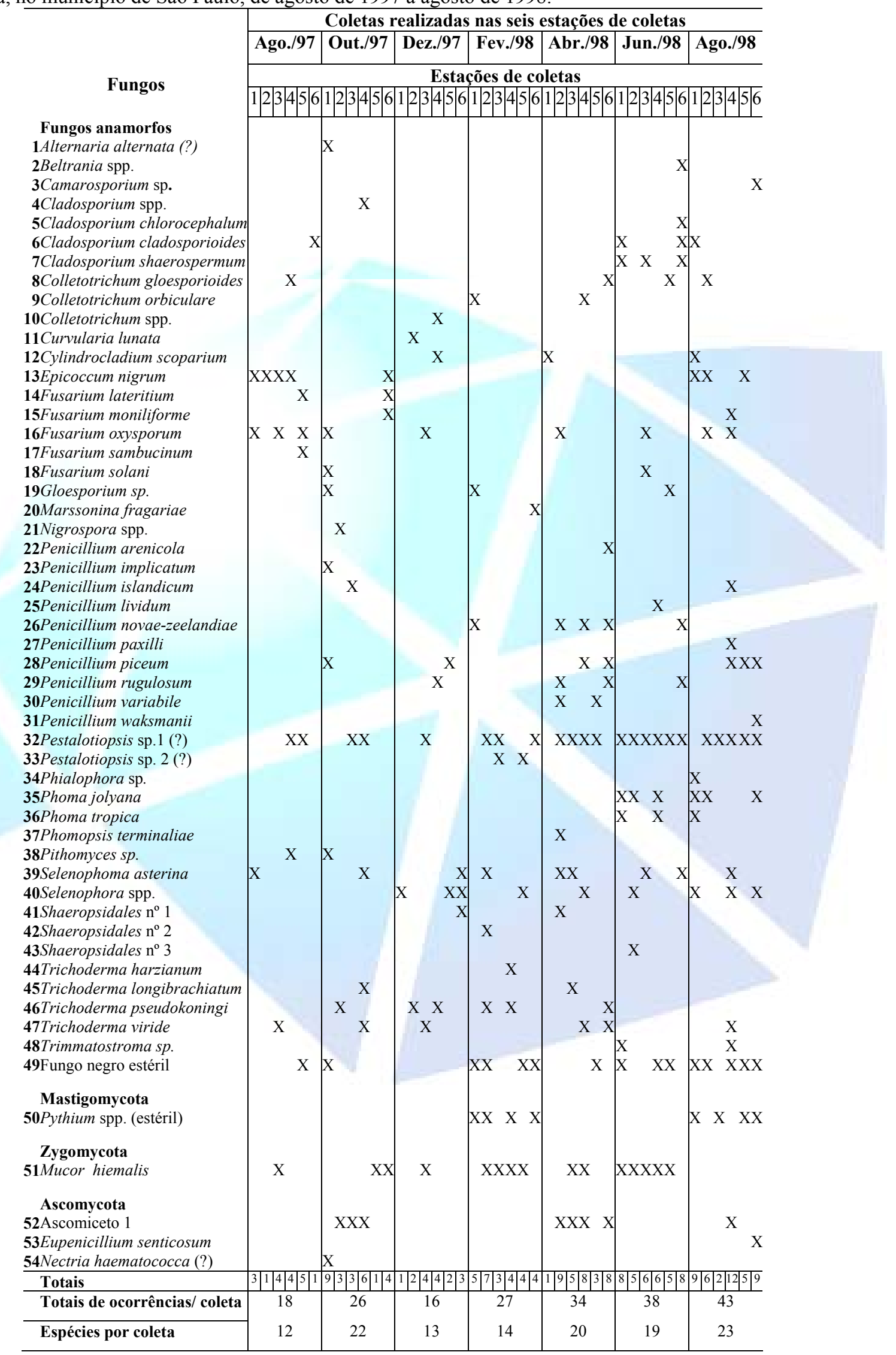


Doze táxons foram exclusivos do ambiente terrestre, vinte táxons foram exclusivos do ambiente aquático e 34 táxons foram comuns aos dois ambientes, portanto as duas micotas apresentaram $68 \%$ de similaridade entre si. Os resultados corroboram com a hipótese de que as folhas submersas oferecem melhores condições para a colonização de fungos do que aquelas de ambiente terrestre (SCHOENLEINCRUSIUS; MILANEZ, 1998). Os táxons estão distribuídos em 59 fungos anamórfos, quatro linhagens distintas de Ascomycota, uma linhagem de Basidiomycota, um representante de Mastigomycota, e uma linhagem de Zygomycota. As micotas apresentaram a tendência de abrangerem grupos de fungos cosmopolitas, como: Penicillium, Fusarium, Trichoderma e Pestalotiopsis.

O predomínio dos fungos anamórfos pode refletir a importância desse grupo como decompositor de substratos foliares ou pode ainda ser resultado do método de isolamento e do meio de cultura empregado, que poderia ter favorecido o crescimento dos fungos esporulantes.

Segundo Christensen (1989), índices de similaridade em torno de 70\% para ambientes temperados indicam proximidades entre as populações fúngicas. No entanto não há dados cumulativos para as regiões de clima tropical que possam indicar qual é o índice adequado para se considerar as micotas similares (SCHOENLEIN-CRUSIUS; MILANEZ, 1998). Provavelmente este índice seria bem mais baixo devido ao maior número de espécies existentes nos ambientes tropicais.

\subsection{Influência dos meses de coleta sobre a diversidade e quantidade dos fungos}

As folhas do ambiente terrestre apresentaram maior número de táxons em abril/98 (24, Tabela 1a), época de poucas chuvas, e o menor número foi verificado em outubro/97 (10, Tabela 1a), quando o número de colônias foi elevado (118 colônias) e a precipitação pluviométrica foi maior (Tabela 2a). O número de colônias pode não estar diretamente relacionado com a diversidade das espécies. No ambiente aquático, o maior número de táxons ocorreu em agosto/98 (23, Tabela 1b), no período seco e frio, enquanto que o maior número de colônias de fungos foi verificado no período úmido e quente, dezembro/97 (82 colônias Tabela 2b).

Tabela 2a - Variáveis abióticas medidas durantes as coletas e teor de nutrientes das folhas do ambiente (médias das estações de coleta)

\begin{tabular}{|c|c|c|c|c|c|c|c|c|c|c|}
\hline Variáveis & $\begin{array}{c}\text { Ago } \\
97\end{array}$ & $\begin{array}{c}\text { Out } \\
97\end{array}$ & $\begin{array}{c}\text { Dez } \\
97\end{array}$ & $\begin{array}{c}\text { Fev } \\
98\end{array}$ & $\begin{array}{c}\text { Abr } \\
98\end{array}$ & $\begin{array}{c}\text { Jun } \\
98\end{array}$ & $\begin{array}{c}\text { Ago } \\
98\end{array}$ & $\begin{array}{l}\text { Análise de } \\
\text { Variância }\end{array}$ & $\begin{array}{l}\text { Teste de } \\
\text { Tukey }\end{array}$ & $\begin{array}{l}\text { Variância } \\
\text { entre } \\
\text { Ambientes }\end{array}$ \\
\hline $\mathbf{N}\left(\mathrm{g} \cdot \mathrm{kg}^{-1}\right)$ & 13,1 & 9,7 & 9,0 & 7,9 & 11,5 & 11,2 & 12,7 & $*$ & $*$ & \\
\hline$P\left(g \cdot \mathrm{kg}^{-1}\right)$ & 0,3 & 0,1 & 0,2 & 0,1 & 0,3 & 0,1 & 0,1 & $*$ & $*$ & \\
\hline$K\left(\mathbf{g} \cdot \mathrm{kg}^{-1}\right)$ & 4,1 & 2,5 & 3,1 & 3,7 & 3,4 & 1,4 & 1,4 & $*$ & $*$ & $*$ \\
\hline $\mathrm{Ca}\left(\mathrm{g} \cdot \mathrm{kg}^{-1}\right)$ & 6,4 & 7,3 & 6,2 & 7,5 & 7,5 & 6,7 & 5,1 & & & \\
\hline $\operatorname{Mg}\left(g \cdot \mathbf{k g}^{-1}\right)$ & 1,7 & 1,2 & 1,2 & 1,4 & 1,5 & 1,4 & 1,6 & & & \\
\hline $\mathrm{S}\left(\mathrm{g} \cdot \mathrm{kg}^{-1}\right)$ & 2,7 & 1,7 & 1,5 & 1,5 & 1,4 & 1,1 & 1,0 & $*$ & $*$ & \\
\hline Bo $\left(\mathrm{mg} \cdot \mathrm{kg}^{-1}\right)$ & 51 & 37 & 45 & 38 & 27 & 31 & 37 & * & $*$ & $*$ \\
\hline $\mathrm{Cu}\left(\mathrm{mg} \cdot \mathrm{kg}^{-1}\right)$ & 18 & 19 & 12 & 9 & 15 & 18 & 22 & & & $*$ \\
\hline $\mathrm{Fe}\left(\mathrm{mg} \cdot \mathrm{kg}^{-1}\right)$ & 1799 & 1320 & 213 & 587 & 1810 & 1053 & 962 & & & $*$ \\
\hline $\operatorname{Mn}\left(\mathbf{m g} \cdot \mathbf{k g}^{-1}\right)$ & 600 & 608 & 703 & 655 & 528 & 625 & 678 & & & \\
\hline $\mathrm{Zn}\left(\mathrm{mg} \cdot \mathrm{kg}^{-1}\right)$ & 48 & 30 & 24 & 29 & 23 & 35 & 46 & $*$ & $*$ & $*$ \\
\hline Precipitação (mm) & 97,1 & 167,8 & 222,1 & 239,5 & 52,3 & 20,8 & 41,0 & $*$ & $*$ & \\
\hline Colônias totais & 45 & 118 & 41 & 38 & 70 & 71 & 44 & $*$ & $*$ & \\
\hline
\end{tabular}


Tabela $2 \mathrm{~b}$ - Variáveis abióticas medidas durantes as coletas e teor de nutrientes das folhas do ambiente aquático (médias das estações de coleta).

\begin{tabular}{|c|c|c|c|c|c|c|c|c|c|}
\hline Variáveis & $\begin{array}{c}\text { Ago } \\
97\end{array}$ & $\begin{array}{l}\text { Out } \\
97\end{array}$ & $\begin{array}{c}\text { Dez } \\
97\end{array}$ & $\begin{array}{c}\text { Fev } \\
98\end{array}$ & $\begin{array}{c}\text { Abr } \\
98\end{array}$ & $\begin{array}{c}\text { Jun } \\
\mathbf{9 8}\end{array}$ & $\begin{array}{c}\text { Ago } \\
\mathbf{9 8}\end{array}$ & $\begin{array}{c}\text { Análise de } \\
\text { Variância }\end{array}$ & $\begin{array}{l}\text { Teste de } \\
\text { Tukey }\end{array}$ \\
\hline$N\left(g \cdot k^{-1}\right)$ & 9,4 & 7,0 & 10,1 & 9,2 & 13,0 & 11,3 & 10,9 & & \\
\hline$P\left(g \cdot k^{-1}\right)$ & 0,3 & 0,1 & 0,1 & 0,1 & 0,4 & 0,1 & 0,1 & * & * \\
\hline$K\left(\mathbf{g} \cdot \mathbf{k g}^{-1}\right)$ & 2,4 & 1,5 & 2,0 & 2,2 & 1,7 & 1,3 & 1,3 & & \\
\hline $\mathrm{Ca}\left(\mathrm{g} \cdot \mathrm{kg}^{-1}\right)$ & 4,3 & 6,8 & 8,1 & 6,2 & 8,6 & 7,0 & 7,0 & $*$ & $*$ \\
\hline $\operatorname{Mg}\left(g \cdot \mathbf{k g}^{-1}\right)$ & 0,8 & 0,8 & 0,9 & 1,0 & 1,0 & 1,3 & 1,0 & & \\
\hline$S\left(\mathbf{g} \cdot \mathbf{k g}^{-1}\right)$ & 3,2 & 2,5 & 1,2 & 1,0 & 1,4 & 1,1 & 0,9 & $*$ & $*$ \\
\hline Bo $\left(\mathbf{m g} \cdot \mathbf{k g}^{-1}\right)$ & 31 & 26 & 36 & 36 & 27 & 33 & 32 & & \\
\hline $\mathrm{Cu}\left(\mathrm{mg}^{\prime} \cdot \mathrm{kg}^{-1}\right)$ & 35 & 22 & 17 & 14 & 18 & 18 & 27 & & \\
\hline $\mathrm{Fe}\left(\mathbf{m g} \cdot \mathbf{k g}^{-1}\right)$ & 12650 & 4037 & 995 & 907 & 1810 & 1336 & 1652 & * & * \\
\hline $\operatorname{Mn}\left(\mathrm{mg}^{\prime} \cdot \mathrm{kg}^{-1}\right)$ & 553 & 466 & 862 & 546 & 528 & 629 & 545 & & \\
\hline $\mathrm{Zn}\left(\mathbf{m g} \cdot \mathrm{kg}^{-1}\right)$ & 32 & 24 & 40 & 21 & 23 & 31 & 27 & * & $*$ \\
\hline Precipitação (mm) & 97,1 & 167,8 & 222,1 & 239,5 & 52,3 & 20,8 & 41,0 & $*$ & $*$ \\
\hline Temperatura ${ }^{\circ} \mathrm{C}$ & 18,7 & 19,1 & 23,6 & 27,7 & 20,1 & 15,9 & 24,8 & * & $*$ \\
\hline $\mathrm{pH}$ & 4,8 & 7,6 & 7,2 & 7,7 & 7,4 & 6,2 & 6,2 & * & * \\
\hline $\begin{array}{l}\text { Condutividade } \\
\left(\mu \mathrm{S} \cdot \mathrm{cm}^{-1}\right)\end{array}$ & 81,1 & 127,2 & 106,4 & 121,7 & 90,4 & 102,0 & 79,0 & * & * \\
\hline $\begin{array}{l}\text { Oxigênio dissolvido } \\
\left(\mathrm{mgO}_{2} \cdot \mathrm{L}^{-1}\right)\end{array}$ & 6,93 & 7,17 & 5,81 & 5,30 & 5,60 & 7,51 & 7,79 & * & \\
\hline $\begin{array}{l}\text { Material total em } \\
\text { suspensão }\left(\mathrm{mg} \cdot \mathrm{L}^{-1}\right)\end{array}$ & - & 35,3 & 13,5 & 31,1 & 16,7 & 22,5 & - & & \\
\hline $\begin{array}{l}\text { Material inorgânico } \\
\text { em suspensão }\left(\mathrm{mg} \cdot \mathrm{L}^{-1}\right)\end{array}$ & - & 22,8 & 6,2 & 20,0 & 16,7 & 15,8 & - & & \\
\hline $\begin{array}{l}\text { Material orgânico em } \\
\text { suspensão }\left(\mathrm{mg} \cdot \mathrm{L}^{-1}\right)\end{array}$ & - & 11,2 & 5,5 & 11,1 & 8,9 & 5,8 & & & \\
\hline Colônias totais & 41 & 79 & 82 & 70 & 69 & 56 & 47 & $*$ & $*$ \\
\hline
\end{tabular}

Os resultados foram dependentes do fator "datas das coletas" no ambiente submerso, com tendência de ter maior número de táxons e menor número de colônias no período seco e frio. Nesse período as águas apresentaram valores menores de temperatura e condutividade e maiores valores de OD. Já a diversidade tendeu a diminuir e o número de colônias a aumentar no período úmido e quente. O teste de Spearman demostrou existir, ao nível de 9\%, comportamento antagônico da diversidade e os números de colônias de fungos em ambiente aquático. A maior disponibilidade de substrato degradável que é importado ao manancial pelas chuvas no verão, poderia estar justificando a atividade microbiana aí presente, diminuindo o $\mathrm{O}_{2}$ dissolvido na água, favorecendo o desenvolvimento em maior abundância de espécies fúngicas adaptadas ao déficit desse gás na água.

As menores similaridades entre as micotas obtidas nos dois ambientes tenderam a acompanhar os meses de maior precipitação (Tabela 3a), demonstrando a possível influência das chuvas na obtenção desses resultados. 
Tabela 3a - Similaridade (\%, em vermelho) calculada pelo índice de Sorensen entre as micotas das folhas submersas e das folhas secas coletadas às margens da Represa do Guarapiranga, São Paulo, SP, confrontando-se os ambientes de coleta.

\begin{tabular}{|c|c|c|c|c|c|c|c|c|c|}
\hline \multirow[b]{3}{*}{ F. } & \multirow[b]{4}{*}{$\mathrm{Ago} / 97$} & \multicolumn{8}{|c|}{ Folhas submersas } \\
\hline & & & $\begin{array}{c}\text { Ago } \\
97\end{array}$ & $\begin{array}{l}\text { Out } \\
97\end{array}$ & $\begin{array}{c}\text { Dez } \\
97\end{array}$ & $\begin{array}{c}\mathrm{FeV} \\
98\end{array}$ & $\begin{array}{c}\text { Abr } \\
98\end{array}$ & $\begin{array}{c}\text { Jun } \\
98\end{array}$ & $\begin{array}{c}\text { Ago } \\
98\end{array}$ \\
\hline & & Táxons & 12 & 22 & 13 & 14 & 20 & 19 & 23 \\
\hline $\mathbf{S}$ & & 13 & 40,0 & & & & & & \\
\hline e & Out/97 & 10 & & $\mathbf{3 7 , 5}$ & & & & & \\
\hline c & Dez/97 & 13 & & & 46,1 & & & & \\
\hline $\mathbf{a}$ & Fev/98 & 15 & & & & 34,5 & & & \\
\hline $\mathbf{s}$ & $\mathrm{Abr} / 98$ & 24 & & & & & 68,2 & & \\
\hline & Jun/98 & 18 & & & & & & 54,0 & \\
\hline & Ago/98 & 16 & & & & & & & 51,3 \\
\hline
\end{tabular}

Tabela 3b - Similaridade (\%) calculada pelo índice de Sorensen entre as micotas das folhas submersas e das folhas secas coletadas às margens da Represa do Guarapiranga, São Paulo, SP, confrontando-se as coletas bimestrais de cada ambiente.

\begin{tabular}{lcccccccccccc}
\hline \multicolumn{1}{c}{ Folhas submersas } & \multicolumn{1}{c}{ Folhas secas } \\
Mêses & Out & Dez & Fev & Abr & Jun & Ago & Out & Dez & Fev & Abr & Jun & Ago \\
& 97 & 97 & 98 & 98 & 98 & 98 & 97 & 97 & 98 & 98 & 98 & 98 \\
\hline Ago/97 & 53,0 & 40,0 & 31,0 & 43,7 & 45,0 & 45,8 & 17,4 & 23,0 & 28,6 & 27,0 & 38,7 & 34,5 \\
Out/97 & & 40,0 & 27,8 & 47,6 & 29,3 & 44,4 & & 26,1 & 64,0 & 52,9 & 42,9 & 46,1 \\
Dez/97 & & & 37,0 & 66,7 & 37,5 & 38,9 & & & 21,4 & 21,6 & 19,3 & 27,6 \\
Fev/98 & & & & 47,0 & 42,0 & 27,0 & & & & 41,0 & 36,3 & 45,2 \\
Abr/98 & & & & & 46,1 & 46,5 & & & & & 61,9 & 60,0 \\
Jun/98 & & & & & & 47,6 & & & & & & 58,8 \\
\hline
\end{tabular}

Tabela 3c - Similaridade (\%, em vermelho) calculada pelo índice de Sorensen entre as micotas das folhas submersas e das folhas secas coletadas às margens da Represa do Guarapiranga, São Paulo, SP, confrontando-se os ambientes e discriminando-se as estações de coleta.

\begin{tabular}{l|l|lllllll}
\hline & & \multicolumn{2}{l}{ F. Submersas } & & & & & \\
\hline \multicolumn{2}{r}{ Pontos } & & 1 & 2 & 3 & 4 & 5 & 6 \\
\hline F. & & Táxons & 23 & 21 & 13 & 29 & 14 & 17 \\
S & 1 & 21 & $\mathbf{4 5 , 4}$ & & & & & \\
e & 2 & 22 & & $\mathbf{5 5 , 8}$ & & & & \\
c & 3 & 14 & & & $\mathbf{3 7 , 0}$ & & & \\
a & 4 & 18 & & & & $\mathbf{5 5 , 3}$ & & \\
s & 5 & 21 & & & & & $\mathbf{3 4 , 3}$ & \\
& 6 & 20 & & & & & & $\mathbf{6 4 , 9}$
\end{tabular}

Os fungos do ambiente terrestre se desenvolveram melhor no verão em condições de umidade elevada, pois requerem suprimento de água constante implicando numa diversidade maior. Com maior número de espécies de fungos 
decompondo as folhas em épocas chuvosas, a probabilidade de se isolar micotas parecidas nos dois ambientes diminui, pois o universo amostral foi aumentado.

Observou-se que no ambiente aquático, quase todos os índices de similaridade encontrados foram próximos dos valores entre $40 \%$ a $50 \%$, enquanto que aqueles das micotas isoladas nas folhas do ambiente terrestre tiveram maior flutuação, tendo vários índices abaixo de $50 \%$ de similaridade (Tabela $3 \mathrm{~b}$ ), demonstrando que o ambiente aquático pode estar menos sujeito às flutuações sazonais que o terrestre, devido às características físicas e químicas intrínsecas da água.

Quando foram comparadas as micotas das diferentes coletas bimestrais em cada estação de coleta o índice de Sorensen indicou diferenças significativas entre a micota isolada no mês de dezembro com todas as outras demais das estações de coleta do ambiente aquático e com metade das estações de coleta do ambiente terrestre. No ambiente aquático, os valores das variáveis de dezembro foram diferentes estatisticamente daqueles encontrados nos demais meses de coletas. Vários estudos anteriores demonstraram que a atividade microbiana e a decomposição de folhas nas águas são reguladas pela quantidade de folhedo e por fatores ambientais aí presentes, temperatura, concentração de nutrientes dissolvidos e pH (PASCOAL; CÁSSIO, 2004). Bärlocher e Graça (2002) não observaram um padrão sazonal claro em relação à esporulação dos fungos, mas verificaram um pico máximo algumas semanas após o evento de queda das folhas. Esses autores encontraram nas regiões de reflorestamento de eucaliptos menor diversidade de hifomicetos aquáticos do que nas regiões de mata ciliar natural.

\subsection{Influência das estações de coleta sobre os fungos (ação antrópica).}

As seqüências do menor para o maior número de táxons encontrados nas estações de coleta, diferiram muito comparando os ambientes terrestre e aquático, indicando que os resultados encontrados podem ser independentes (Tabela 3c). Podese observar que o número de táxons foi praticamente idêntico entre as estações de coleta do ambiente terrestre, com exceção da estação 3 que teve o número de táxons mais baixo. No ambiente aquático a estação 3 também apresentou o número mais baixo de táxons seguido daquele obtido na estação 5 .

A poluição orgânica, sob forma de despejos clandestinos, refletida na elevação dos teores de material em suspensão na água, pode ter atuado sobre a diversidade dos fungos, elevando o número de táxons nas folhas das estações poluídas do ambiente aquático, pois a flutuação do número de táxons nas estações de coleta acompanhou a flutuação dos teores de material em suspensão (Tabela 4). As estações de coleta que mostraram menor similaridade entre as micotas das folhas, comparando-se os dois ambientes, independentemente da época de coleta, foram as estações 3 e 5, apesar de apresentarem menor número de táxons isolados. Possivelmente, a flutuação da matéria total em suspensão na água justifique as similaridades baixas entre as micotas dos dois ambientes dessas estações. Observou-se que elas apresentaram menores 
médias do teor de material total $\left(18,0\right.$ e $\left.6,2 \mathrm{mg} \cdot \mathrm{L}^{-1}\right)$, orgânico $\left(9,5 \mathrm{e} 3,3 \mathrm{mg} \cdot \mathrm{L}^{-1}\right)$ e inorgânico $\left(9,8\right.$ e $\left.2,3 \mathrm{mg} \cdot \mathrm{L}^{-1}\right)$ dissolvido na água.

Tabela 4 - Médias dos parâmetros abióticos medidos na água que banha as margens da Represa do Guarapiranga nas seis estações de coleta estudadas.

\begin{tabular}{|c|c|c|c|c|c|c|c|}
\hline Estações & Temp. ${ }^{\circ} \mathrm{C}$ & pH & $\begin{array}{c}\text { Condutividade } \\
\cdot \mu \mathrm{S} \cdot \mathrm{cm}^{-1}\end{array}$ & 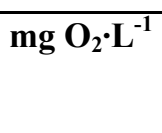 & $\begin{array}{c}\text { Material } \\
\text { total } \\
\text { mg. } \mathbf{L}^{-1}\end{array}$ & $\begin{array}{c}\text { Material } \\
\text { orgânico } \\
\mathbf{m g} \cdot \mathbf{L}^{-1}\end{array}$ & $\begin{array}{c}\text { Material } \\
\text { inorgânico } \\
\mathrm{mg}^{\prime} \cdot \mathrm{L}^{-1}\end{array}$ \\
\hline 1 & 21,3 & 7,38 & 113,9 & 6,92 & 24,4 & 7,5 & 16,9 \\
\hline 2 & 22,1 & 7,04 & 123,6 & 6,45 & 44,3 & 11,1 & 36,9 \\
\hline 3 & 22,5 & 6,94 & 130,5 & 6,00 & 18,0 & 9,5 & 9,8 \\
\hline 4 & 21,4 & 6,99 & 99,7 & 6,75 & 26,6 & 10,0 & 15,6 \\
\hline 5 & 22,6 & 6,50 & 43,1 & 6,50 & 6,2 & 3,3 & 2,3 \\
\hline 6 & 21,3 & 7,18 & 113,7 & 6,73 & 24,1 & 9,3 & 16,1 \\
\hline $\begin{array}{l}\text { Análise } \\
\end{array}$ & $*$ & & $*$ & & & & \\
\hline \multicolumn{8}{|l|}{ Variância } \\
\hline Teste de Tukey & * & $*$ & * & & & & \\
\hline
\end{tabular}

Legenda: $\left(^{*}\right)$ significativo

Nas estações de coleta 2 e 6, que são influenciadas por córregos poluídos, e na estação de coleta 4 que também recebe carga alta de poluição na água, foram encontradas médias altas do material total $\left(44,3 \mathrm{mg} \cdot \mathrm{L}^{-1}, 26,6 \mathrm{mg} \cdot \mathrm{L}^{-1}\right.$ e $\left.24,1 \mathrm{mg} \cdot \mathrm{L}^{-1}\right)$, orgânico $\left(11,1 \mathrm{mg} \cdot \mathrm{L}^{-1} 10,0 \mathrm{mg} \cdot \mathrm{L}^{-1}\right.$ e $\left.9,3 \mathrm{mg} \cdot \mathrm{L}^{-1}\right)$ e inorgânico $\left(36,9 \mathrm{mg} \cdot \mathrm{L}^{-1}, 16,1\right.$ $\mathrm{mg} \cdot \mathrm{L}^{-1}$ e $\left.15,6 \mathrm{mg} \cdot \mathrm{L}^{-1}\right)$ em suspensão na água. Essas estações tiveram altos índices de similaridade nessas comparações, apesar de apresentarem maiores números de táxons de fungos.

A micota proveniente de folhas recém-caídas teria, portanto, maiores chances de continuar colonizando essas folhas, mesmo estando submersas, pois parte dos recursos energéticos estariam sendo supridos pela água, diminuindo assim a competição por nutrientes das folhas por fungos que poderiam "desalojar" os já estabelecidos (nas folhas), contribuindo para a similaridade alta das micotas dos dois ambientes encontradas nas estações de coleta 2,4 e 6.

Observou-se que nas estações submetidas a elevado impacto ambiental (estações 1 e 6), que receberam altas doses de sulfato de cobre e/ou a introdução de matéria orgânica (esgotos clandestinos), as micotas das folhas submersas mostraram a tendência de serem diferentes das micotas isoladas nas folhas secas ao longo do período estudado. Situação contrária é verificada nas estações submetidas a menor influência antrópica (estações 3 e 5), registrando-se maiores similaridades entre as micotas dos dois ambientes. Mesmo sendo escassos os dados disponíveis na literatura para justificar tais observações, pode-se formular a hipótese de que a mudança da diversidade da micota nas folhas submersas seja uma das respostas que a influência antrópica possa provocar.

Comunidades fúngicas podem ser diretamente afetadas por distúrbios químicos ou físicos (antrópicos ou não). Os fungos ainda podem responder indiretamente aos 
efeitos do distúrbio. Fungos cosmopolitas e tolerantes ao estresse são normalmente favorecidos pelo distúrbio enquanto que espécies mais sensíveis e mais competitivas são afetadas negativamente por este (MILLER; LODGE, 1997). Niyogi et al. (2001) propuseram um modelo no qual a biodiversidade tem um baixo limiar de resposta ao estresse antrópico, em que a biomassa e o funcionamento são estáveis ou aumentam sob estresse baixo a moderado e diminui sob condições de estresse elevado. Os recursos locais e o clima determinam a diversidade. Em geral o número de espécies (diversidade) é baixo quando os recursos são escassos ou superabundantes (HUSTON, 1994).

Estudo realizado em Portugal mostrou que maior taxa de decomposição de folhas ocorreu no trecho mais poluído de um rio, juntamente com maior quantidade de biomassa fúngica. A menor taxa de decomposição ocorreu em outro ponto poluído com menor taxa de $\mathrm{O}_{2}$ dissolvido e de biomassa fúngica, sugerindo que a atividade fúngica depende, além da concentração de nutrientes, também de outros fatores. A decomposição de folhas tende a ser diretamente proporcional às quantidades de nutrientes, nitrogênio e/ou fósforo (PASCOAL; CÁSSIO, 2004). Assim, o fosfato pode aumentar a atividade decompositora e a diversidade de fungos (SUBERKROPP; CHAUVET, 1995, SRIDHAR; BÄRLOCHER, 2000).

Em um rio poluído na Índia, $90 \%$ das espécies foram "perdidas" em comparação com um ponto menos poluído evidenciando que a poluição orgânica restringe severamente a diversidade de hifomicetos aquáticos (RAVIRAJA et al., 1998). Maltby e Booth (1991), em um rio na Inglaterra, observaram uma diversidade menor e taxas de decomposição mais baixas próximo ao efluente poluído. Nas estações de coleta do ambiente aquático aqui estudadas, diversas micotas obtidas nas diferentes épocas de coleta não apresentaram similaridade entre si, mostrando elevada variabilidade de espécies. Possivelmente esse fato possa ser explicado pelo ambiente aquático ser mais dinâmico do que o terrestre.

Pode-se ainda concluir que as micotas das estações de coleta que ainda abrigam vegetação bem preservada ( 3 e 5), mostraram tendência de serem menos variáveis em termos de diversidade, ao longo do período estudado. O número de similaridades nulas foi menor nessas estações, nos dois ambientes, portanto, as micotas dessas duas estações de coleta ( 3 e 5) demonstraram serem menos afetadas pelas alterações climáticas do que as das outras estações. A diversidade fúngica está relacionada com a diversidade vegetal e conseqüentemente também, relacionada com distúrbio antrópico sobre a cobertura vegetal (MILLER; LODGE, 1997, HAWKSWORTH, 2001). Folhas de eucaliptos são substratos pobres para fungos aquáticos (COWLING; WAID, 1963, BUNN, 1986) a possível "preferência" de outros substratos que não estes por geofungos com capacidade de crescer em materiais orgânicos submergido pode estar correlacionada.

As diferenças entre as micotas das diferentes estações de coleta sem se discriminar as épocas de coleta não foram muito acentuadas e praticamente todas as estações de coleta mostraram as mesmas diferenças entre suas micotas, apresentando 
um índice de similaridade entre 40-65\%. A elevada ocorrência de fungos cosmopolitas poderia justificar esses resultados.

\subsection{Influência dos nutrientes das folhas sobre a diversidade e ocorrência dos fungos}

A quantidade de colônias pode refletir a capacidade de proliferação e de colonização dos fungos. No presente estudo, o número de colônias apresentou-se maior nas folhas dos dois ambientes da estação 1, a mais afetada pela aplicação de sulfato de cobre, enquanto o menor número de colônias foi encontrado nas folhas da estação 5, que não recebeu esse algicida (Tabela 5). A vegetação das margens da estação 1 poderia estar acumulando mais cobre do que as das outras estações, já que nas folhas do ambiente terrestre das margens desta estação foram encontrados valores de cobre quatro vezes superior $\left(44 \mathrm{mg} \cdot \mathrm{kg}^{-1}\right)$ que nas folhas das outras estações (média $\left.10,8 \mathrm{mg} \cdot \mathrm{kg}^{-1}\right)$.

Tabela 5a - Macro e micronutrientes encontrados nas folhas coletadas do ambiente terrestre nas margens da Represa do Guarapiranga.

\begin{tabular}{|c|c|c|c|c|c|c|c|c|c|c|c|c|c|}
\hline Estações & $\underset{1}{\mathbf{g} \cdot \mathbf{k g}}$ & $\begin{array}{c}P \\
\mathrm{~g} \cdot \mathrm{kg}^{-1}\end{array}$ & $\underset{\mathbf{g} \cdot \mathbf{k g}^{-1}}{K}$ & $\begin{array}{c}\mathrm{Ca} \\
\mathrm{g}^{\circ} \cdot \mathrm{kg}^{-1}\end{array}$ & $\underset{\mathrm{g} \cdot \mathrm{kg}^{-1}}{\mathbf{M g}}$ & $\underset{\mathbf{g} \cdot \mathbf{k g}}{\mathrm{S}}$ & $\underset{\mathbf{m g} \cdot \mathrm{kg}^{-}}{\mathrm{B}}$ & $\underset{\mathrm{mg} \cdot \mathbf{k g}^{-1}}{\mathrm{Cu}}$ & $\begin{array}{c}\mathrm{Fe} \\
\mathrm{mg} \cdot \mathrm{kg}^{-1}\end{array}$ & $\underset{\mathrm{mg} \cdot \mathrm{kg}^{-1}}{\mathrm{Mn}}$ & $\underset{\mathrm{mg}^{\prime} \mathrm{kg}^{-1}}{\mathrm{Zn}}$ & $\begin{array}{r}\text { Colônias } \\
\text { Totais }\end{array}$ & Espécies \\
\hline 1 & 1,3 & 0,2 & 3,0 & 8,1 & 1,4 & 1,9 & 42 & 44 & 2832 & 776 & 45 & 80 & 21 \\
\hline 2 & 5,5 & 0,1 & 2,2 & 7,4 & 1,5 & 0,9 & 43 & 9 & 1263 & 207 & 21 & 57 & 22 \\
\hline 3 & 14,5 & 0,2 & 2,4 & 4,8 & 1,3 & 2,0 & 35 & 11 & 984 & 1034 & 30 & 56 & 14 \\
\hline 4 & 11,4 & 0,2 & 3,0 & 5,4 & 1,6 & 1,7 & 39 & 11 & 603 & 516 & 33 & 57 & 18 \\
\hline 5 & 11,7 & 0,2 & 1,6 & 6,9 & 1,7 & 1,8 & 32 & 10 & 361 & 441 & 48 & 50 & 21 \\
\hline 6 & 8,5 & 0,1 & 3,8 & 7,5 & 1,2 & 1,0 & 37 & 13 & 460 & 771 & 27 & 61 & 20 \\
\hline $\begin{array}{c}\text { Análise } \\
\text { Variância }\end{array}$ & * & & & $*$ & $*$ & * & & * & $*$ & * & $*$ & $*$ & \\
\hline $\begin{array}{c}\text { Teste de } \\
\text { Tukey }\end{array}$ & $*$ & & & & $*$ & $*$ & & $*$ & * & $*$ & $*$ & $*$ & \\
\hline
\end{tabular}

Tabela $5 \mathrm{~b}$ - Macro e micronutrientes encontrados nas folhas coletadas do ambiente aquático nas margens da Represa do Guarapiranga.

\begin{tabular}{|c|c|c|c|c|c|c|c|c|c|c|c|c|c|}
\hline Estações & $\underset{\mathbf{g} \cdot \mathbf{k g}^{-}}{\mathrm{N}}$ & $\frac{\mathbf{P}}{\mathrm{g} \cdot \mathrm{kg}^{-1}}$ & $\underset{\mathrm{g} \cdot \mathrm{kg}^{-1}}{\mathrm{~K}}$ & $\underset{\mathrm{g} \cdot \mathrm{kg}^{-1}}{\mathrm{Ca}}$ & $\underset{\mathrm{g} \cdot \mathbf{k g}^{-1}}{\mathbf{M g}}$ & $\underset{1}{\mathrm{~g} \cdot \mathbf{k g}^{-}}$ & $\underset{1}{\mathrm{mg} \cdot \mathrm{kg}^{-}}$ & $\begin{array}{c}\mathrm{Cu} \\
\mathrm{mg} \cdot \mathrm{kg}^{-1}\end{array}$ & $\begin{array}{c}\text { Fe } \\
\mathrm{mg} \cdot \mathrm{kg}^{-1}\end{array}$ & $\begin{array}{c}\text { Mn } \\
\mathrm{mg}^{\prime} \mathrm{kg}^{-1}\end{array}$ & $\underset{\mathrm{Zng}}{\mathrm{Zng}}$ & $\begin{array}{c}\text { Colônias } \\
\text { Totais }\end{array}$ & Espécies \\
\hline 1 & 10,2 & 0,2 & 2,2 & 7,4 & 1,1 & 1,8 & 33 & 35 & 4882 & 781 & 33 & 70 & 23 \\
\hline 2 & 8,7 & 0,1 & 1,5 & 10,6 & 1,1 & 1,3 & 31 & 21 & 3218 & 329 & 21 & 68 & 21 \\
\hline 3 & 14,6 & 0,3 & 1,5 & 5,1 & 0,8 & 2,3 & 29 & 27 & 6756 & 939 & 27 & 62 & 13 \\
\hline 4 & 10,5 & 0,2 & 2,1 & 5,3 & 1,0 & 1,9 & 34 & 12 & 1345 & 355 & 23 & 58 & 29 \\
\hline 5 & 9,3 & 0,2 & 1,4 & 5,1 & 0,8 & 1,1 & 31 & 10 & 1916 & 495 & 43 & 54 & 14 \\
\hline 6 & 7,8 & 0,1 & 2,1 & 7,4 & 1,0 & 1,1 & 33 & 22 & 1627 & 645 & 24 & 67 & 27 \\
\hline $\begin{array}{c}\text { Análise } \\
\text { Variância } \\
\end{array}$ & $*$ & $*$ & & $*$ & & * & & $*$ & & * & $*$ & & \\
\hline $\begin{array}{l}\text { Teste de } \\
\text { Tukey }\end{array}$ & $*$ & & & $*$ & & * & & $*$ & & $*$ & $*$ & & \\
\hline
\end{tabular}

Talvez no ambiente terrestre o alto teor de ferro contido nas folhas da estação de coleta $1\left(2832 \mathrm{mg} \cdot \mathrm{kg}^{-1}\right)$, que foi em torno de quatro vezes maior do que a média dos valores desse elemento encontrado nas folhas das outras estações (média: 734 
$\mathrm{mg} \cdot \mathrm{kg}^{-1}$ ), também possa ter contribuído para os maiores números de colônias encontrados no folhedo seco dessa estação. $\mathrm{O}$ ferro está envolvido na inibição da germinação de esporos de certos tipos de fungos. A influência antrópica na estação 1 pode estar selecionando espécies mais resistentes, que conseguem estabelecer-se nas folhas em abundância devido à pouca competição com outras espécies menos resistentes aos altos teores de cobre e de ferro presentes nas folhas dessa estação.

A estação 2, submetida à poluição orgânica e à constante retirada de seu folhedo, apresentou o folhedo terrestre com os menores teores de nitrogênio, fósforo, enxofre, cobre, manganês e zinco (Tabela 5a). No ambiente aquático, o folhedo teve menores teores de fósforo, manganês e zinco e os maiores de cálcio (Tabela $5 b$ ).

A estação de coleta 3 , que apresenta vegetação preservada, mostrou no folhedo terrestre com elevados teores de nitrogênio, enxofre e manganês e baixos de cálcio (Tabela 5a). A estação 5, que também tem sua vegetação bem preservada, apresentou no folhedo terrestre os maiores teores de magnésio e zinco e os menores valores de potássio, boro e ferro (Tabela 5a). No ambiente aquático o folhedo da estação 3 apresentou os maiores valores de nitrogênio, fósforo, enxofre e manganês (Tabela $5 b)$. O folhedo submerso da estação 5 apresentou os maiores teores de zinco e os menores teores de potássio, cobre; e junto com a estação 3 os menores valores de cálcio (Tabela 5b). Possivelmente os baixos teores de cálcio possam ter contribuído com os baixos números de táxons isolados nas estações de coleta 3 e 5 .

$\mathrm{O}$ teste de Spearman demonstrou existir nos dois ambientes uma correlação positiva entre o número de colônias de fungos e os teores de cálcio das folhas em decomposição. $\mathrm{O}$ teor de nutrientes presentes nas folhas pode ter exercido influência sobre a diversidade dos fungos. Nas folhas submersas o número de táxons por mês de coleta manteve correlação positiva com os teores de nitrogênio e fósforo das folhas; o número de ocorrências por estação de coleta teve correlação positiva com o teor de magnésio das folhas. Nas folhas secas, o número de táxons por mês correlacionou-se negativamente com os teores de potássio, enxofre e boro, contido nas folhas. Este último se correlacionou negativamente com o número de ocorrências nas estações de coleta e também com o número de ocorrências por mês.

$\mathrm{O}$ folhedo submerso conteve mais cobre e ferro do que o folhedo terrestre, que apresentou os maiores teores de magnésio e zinco. Os teores de cálcio e potássio nas folhas da represa apresentam valores menores do que em outros ecossistemas. Os folhedos terrestre e aquático podem ser considerados pobres na maioria dos macro e microelementos, significando que sua contribuição como fonte de nutrientes pode ser limitada. A influência antrópica, a qual a represa vem sendo submetida, como o despejo de poluentes orgânicos, a sulfatação das águas e a modificação da vegetação das margens, pode ter atuado sobre os teores de nutrientes das folhas, sobre a diversidade e quantidade de fungos, e refletiu-se na similaridade das micotas obtidas das folhas dos ambientes aquático e terrestre. 


\section{AGRADECIMENTOS}

Este estudo é parte da dissertação de mestrado do primeiro autor, defendida no Instituto de Biociências, UNESP, Campus de Rio Claro, SP. Agradecemos a FAPESP pela concessão da bolsa de Mestrado, e ao auxílio financeiro ao projeto temático (processo FAPESP 1996/7369-2). Agradecemos ao Prof. Dr. Antonio Carlos Simões Pião pela análise estatística dos dados, a Profa. Dra. Ana Rosely Picollo Grandi pela ajuda nas identificações taxonômicas.

\section{REFERÊNCIAS}

BÄRLOCHER, F. The role of fungi in the nutrition of stream invertebrates. Botanical Journal of the Linnean Society, London, v. 91, n. 1/2, p. 83-94, 1985.

BÄRLOCHER, F.; GRAÇA, M. A. S. Exotic riparian vegetation lowers fungal diversity but not leaf decomposition in Portuguese streams. Freshwater Biology, Oxford, v. 47, n. 6, p. 1123-1135, 2002. http://dx.doi.org/10.1046/j.13652427.2002.00836.x

BERGAMIN, A. F.; KIMATI, H. Variedades resistentes. In: GALLI, F. (Ed.) Manual de fitopatologia: princípios e conceitos. 3. ed. São Paulo: Ceres, 1995. v. 1, cap. 17 , p. 297-324.

BUNN, S. E. Origin and fate of organic matter in Australian upland streams. In: DeDEKKER, P.; WILliAMS, W. D. (Ed.) Limnology in Australia. Australia: CSIRO, 1986. p. 277-291.

CHRISTENSEN, M. A view of fungal ecology. Mycologia, Lancaster, v. 81, p. 1-19, 1989. Disponível em: http://www.jstor.org/view/00275514/ap060420/06a00020/0 Acesso em: 31 jan. 2007.

COMPANHIA DE TECNOLOGIA DE SANEAMENTO AMBIENTAL. Avaliação das águas para fins recreacionais - Reservatório de Guarapiranga. São Paulo: Secretaria do Meio Ambiente, CETESB, 1992.

COMPANHIA DE TECNOLOGIA DE SANEAMENTO AMBIENTAL. Relatório de Qualidade das Águas Interiores do Estado de São Paulo - 1997. São Paulo: Secretaria do Meio Ambiente CETESB, 1998.

COWLING, S. W.; WAID, J. S. Aquatic hyphomycetes in Australia. Australian Journal of Science, Melbourne, v. 26, p. 122-123, 1963. 
GESSNER, M. O.; CHAUVET, E. Importance of stream microfungi in controlling breakdown rates of leaf litter. Ecology, Durham, v. 75, n. 6, p. 1807-1817, 1994. Disponível em: http://www.jstor.org/view/00129658/di960361/96p0189o/0 Acesso em: 31 jan. 2007.

HAILA, Y.; KOUKI, J. The phenomenon of biodiversity in conservation biology. Annales Zoologici Fennici, Helsinki, v. 31, n. 1, p. 5-18, 1994.

HAWKSWORTH, D. L. The magnitude of fungal diversity: the 1,5 million species estimate revisited. Mycological Research, Cambridge, v. 105, n. 12, p. 1422-1432, 2001. http://dx.doi.org/10.1017/S0953756201004725

HUSTON, M. A. Biological diversity. Cambridge: Cambridge University Press, 1994.

MALTBY, L.; BOOTH, R. The effect of coalmine effluent on fungal assemblages and leaf breakdown. Water Research, Oxford, v. 25, p. 247-250, 1991.

MILANEZ, A. I. A atuação dos fungos nos ecossistemas. In: CONGRESSO DA SOCIEDADE BOTÂNICA DE SÃO PAULO, 9., 1992, São Paulo. Anais... São Paulo: SBSP, FAPESP, 1995. p. 67-72.

MILLER, R. M.; LODGE, D. J. Fungal response to disturbance: agriculture and forestry. In: WICKLOW, D. T.; SÖDERSTRÖM, B. E (Ed.) The mycota IV environmental and microbial relationships. Berlin: Springler-Verlag, 1997. p. 6584.

MYCOLOGY GUIDEBOOK COMMITTEE (MSA). Mycology Guidebook. Preliminary edition. Chicago: The Mycological Society of America, 1970.

NANTEL, B.; NEUMANN, P. Ecology of ectomycorrhizal-basidiomycete communities on a local vegetation gradient. Ecology, Durham, v. 73, p. 99-117, 1992. Disponível em: http://www.jstor.org/view/00129658/di960342/96p0076t/0 Acesso em: 31 jan. 2007.

NIYOGI, D. K.; LEWIS Jr., W. M.; McKNIGHT, D. M. Litter breakdown in mountain streams affected by mine drainage: biotic mediation of abiotic controls. Ecological Applications, Washington, v. 11, n. 2, p. 506-516, 2001. Disponível em: http://www.jstor.org/view/10510761/sp020003/02x0069q/0 Acesso em: 31 jan. 2007.

PASCOAL, C.; CÁSSIO, F. Contribution of fungi and bacteria to leaf litter decomposition in a polluted river. Applied and Environmental Microbiology, 
Washington, v. 70, n. $\quad 9, \quad$ p. $5266-5273, \quad 2004$. http://dx.doi.org/10.1128/AEM.70.9.5266-5273.2004

PUGH, G. J. F.; BUCKEY, N. G.; MULDER, J. The role of phylloplane fungi in the early colonization of leaves. Symposia Biologica Hungarica, Budapest, v. 11, p. 329-333, 1972.

RAVIRAJA, N. S.; SRIDHAR, K. R.; BÄRLOCHER, F. Breakdown of Ficus and Eucalyptus leaves in an organically polluted river in India: fungal diversity and ecological functions. Freshwater Biology, Oxford, v. 39, p. 537-545, 1998. http://dx.doi.org/10.1046/j.1365-2427.1998.00303.x

RIDDELL, R. W. Permanent stained mycological preparations obtained by slide culture. Mycologia, Lancaster, v. 42, p. 265-270, 1950. Disponível em: http://www.jstor.org/view/00275514/ap060247/06a00080/0 Acesso em: 31 jan. 2007.

SCHOENLEIN-CRUSIUS, I. H.; MILANEZ, A. I. Fungos microscópicos da Mata Atlântica de Paranapiacaba, São Paulo, Brasil. Revista Brasileira de Botânica, São Paulo, v. 21, n. 1, p. 73-79, 1998. http://dx.doi.org/10.1590/S0100$\underline{84041998000300003}$

SRIDHAR, K. R.; BÄRLOCHER, F. Initial colonization, nutrient supply and fungal activity on leaves decaying in streams. Applied and Environmental Microbiology, Washington, v. 66, n. 3, p. 114-119, 2000. Disponível em: http://www.pubmedcentral.nih.gov/articlerender.fcgi?artid=91950 Acesso em 31 jan. 2007.

SUBERKROPP, K.; CHAUVET, E. Regulation of leaf breakdown by fungi in streams: influences of water chemistry. Ecology, Durham, v. 76, p. 1433-1445, 1995. Disponível em: http://www.jstor.org/view/00129658/di960368/96p01182/0 Acesso em: 31 jan. 2007.

SYMONIDES, E. Biological diversity: The role of its evaluation and conservation in the Polish national parks. Wiadomosci Ekologiczne, Warsaw, v. 38, p. 221-237, 1992.

TAUK-TORNISIELO, S. M. Microbiota telúrica de latossolo vermelho-amarelo com cultura de milho (Zea mays) tratado com vinhaça, no município de Rio Claro, SP. Revista de Microbiologia, São Paulo, v. 19, p. 229-234, 1988. 
TAUK-TORNISIELO, S. M.; RUEGGER, M. J. S. Alguns aspectos da microbiota do solo sob vegetação de cerrado, tratado com vinhaça, no município de Corumbataí, SP. Revista de Microbiologia, São Paulo, v. 18, p. 67-76, 1987.

TAUK-TORNISIELO, S. M.; MALAGUTTI, E. N.; MEDEIROS, A. M. Nutrientes, atividades enzimáticas e microrganismos do solo tratado com vinhaça e ou torta de filtro em cultura de cana-de-açúcar. Revista de Microbiologia, São Paulo, v. 21, n. 4, p. 342-349, 1990a.

TAUK-TORNISIELO, S. M.; SHOENLEIN-CRUSIUS, I. H.; PETENATE, A. Nutrientes, atividades enzimáticas e microrganismos do solo tratado com vinhaça e ou torta de filtro em cultura de cana-de-açúcar. Revista de Microbiologia, São Paulo, v. 21, p. 99-108, 1990 b.

TSUI, K. M.; FRYAR, S. C.; HODGKISS, I. J.; HYDE, K. D.; POONYTH, A. D.; TAYLOR, J. E. The effect of human disturbance on fungal diversity in the tropics. Fungal Diversity, Hong Kong, v. 1, p. 19-26, 1998.

ZAK, J. C. Response of soil fungal communities to disturbance. In: CARROLL, G.; WICKLOW, D. T. (Ed.) The fungal community: its organization and role in the ecosystem. New York: Marcel Dekker, 1992. p. 403-425. 